\title{
Flipped learning: an alternative pedagogical approach in the untact age
}

\author{
Oh Young Kwon* \\ Department of Medical Education and Medical Humanities, Kyung Hee University College of Medicine, Seoul, Korea
}

Flipped learning, abbreviated as "FL" is a new pedagogical approach that reverses the order of a typical lecture. It was developed to compensate for the shortcomings of a typical teaching method. Students learn by watching video clips before class and continue to learn through peer discussion in the classroom. The educational benefits of FL like student's positive attitude were revealed in the previous studies.
FL can be a valuable alternative to the existing classes in the untact age of coronavirus disease 2019.

Keywords: Flipped learning, Flipped classroom, Medical education, Active learning

\section{INTRODUCTION}

Teacher-centered learning known as 'lecture' has been the most convenient and typical method for disseminating knowledge for a long time. However, the typical way of lecturing is considered to have made learners be passive at classes (Mazur, 2009). Recently, a variety of new educational modalities have been developed continuously.

The global educational environment has been rapidly changed by the explosion of knowledge and the development of information technology. In particular, learners can learn anywhere, anytime with their personal smart devices in this high-speed internet environment. The remarkable change accelerates the development of new teaching methods. Blended learning, which combines online and offline education was created based on this educational environment and led to the development of flipped learning (FL) (Eapen et al., 2012).

FL is a new student-centered pedagogical model that reverses the order of a typical lecture (Bergmann and Sams, 2012). Students practice their self-directed learning by watching videos by themselves before coming to the classroom and then solve problems through some quizzes and discussions during in-class activity. In FL, teach- ers can help students solve problems faster through discussion instead of giving a long lecture. It has been sporadically occurred in the United Status since the early 2000s and was attempted in a variety of educational fields (Deslauriers et al., 2011). Previous studies have shown that FL can improve student's academic achievement as it highlights motivation, autonomy, and self-directed competence development compared to the traditional ways of teaching (Goh and Ong, 2019; Hinojo Lucena et al., 2019; Koh et al., 2021).

Face-to-face course has been replaced with online course in many fields due to coronavirus disease 2019 (COVID-19) infection. In this situation, the efficacy of a typical lecture might also be unsatisfactory. In a web-based untact educational environment, FL is attracting attention as a new alternative pedagogy that can overcome the limitations of the existing teaching methods. This paper investigates into the structure, application, and educational effect of FL. The purpose of this article is to introduce FL to teachers who want to help students achieve educational outcomes in a nonface-to-face environment.

\section{STRUCTURE OF FLIPPED LEARNING}

FL consists of three essential steps: (a) preclass, (b) in-class, and
${ }^{*}$ Corresponding author: Oh Young Kwon (iD https://orcid.org/0000-0003-0817-2256 Department of Medical Education and Medical Humanities, Kyung Hee University School of Medicine, 26 Kyungheedae-ro, Dongdaemun-gu, Seoul 02447, Korea Email: koy04@khu.ac.kr

Received: April 28, 2021 / Accepted: May 20, 2021
This is an Open Access article distributed under the terms of the Creative Commons Attribution Non-Commercial License (https://creativecommons.org/licenses/by-nc/4.0/) which permits unrestricted non-commercial use, distribution, and reproduction in any medium, provided the original work is properly cited. 


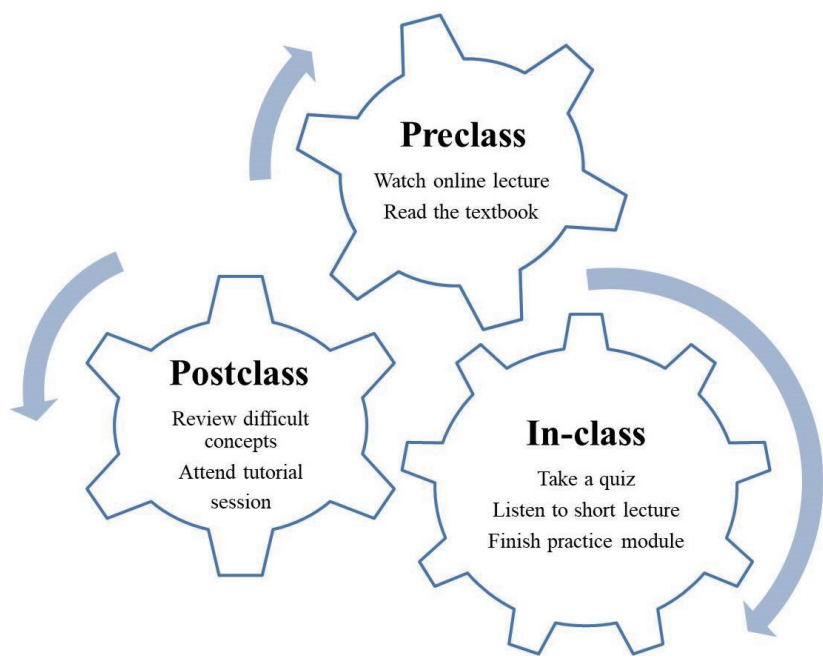

Fig. 1. Structure of flipped learning.

(c) postclass (Fig. 1). In the first step, information transfer is performed by students who begin learning in advance. Checking of prelearning status and peer learning or instruction is enforced in the next step. Usually, relearning and application of knowledge occur in the last step.

\section{Preclass step}

In this step, teachers have to develop a prelearning education module for students. The module should contain learning materials that enable self-directed learning. Prelearning materials of the past included PowerPoint, quiz, and lecture notes, but online video contents are usually replacing those materials. Web-based video contents for FL have merits in that students can control their learning speed based on student level, reduce the burden of learning by identifying what core contents are, and use such contents regardless of time and place. If necessary, students read assigned textbooks in advance. Teacher provides a learning sheet that enables students can summarize the prelearning content.

\section{In-class step}

In this step, teachers can give a 'quiz' to check the prelearning status. This activity can connect between online study and offline one effectively. Teachers should review quiz answers. This quiz activity can also play a role as an assessment tool for organizing learning outcomes and checking student's performance at the end of the class. Teachers proceed with a mini-lecture on a pertinent topic after the quiz activity. Teachers summarize or offer an additional explanation about the video contents provided for preclass learning. Teachers should also prepare the assigned practice module.
Students participate in a variety of activities including group discussion, peer learning, and peer instruction (Chowdhury et al., 2019). Teachers should monitor each student's learning activities, identify what students do not know through continuous assessment, and act as a facilitator on such activities. Teachers can also execute individualized learning for students with learning difficulties.

\section{Postclass step}

In this step, teachers should provide various resources to enable students to perform higher-level application activities. Teachers give a tutorial session to review difficult concepts. Students can carry out information exchange activities and receive feedback by visiting a teacher or using various media like social network service. These activities can enable teachers to monitor student's learning activities and assess mutual sharing and evaluate individual achievements or outcomes during in-class activity.

\section{APPLICATION AND EDUCATIONAL EFFECT OF FLIPPED LEARNING}

FL can be applied in numerous educational settings regardless of subject, but is still widely used in science and medicine which require a lot of learning in a short time. The first use of the term "flipped" was at the chemistry class in high school (Bergmann and Sams, 2012). Since the 1990s, Professor Mazur has developed a peer-in-structure education model that allows students to learn with prelearning materials and solve problems through mutual cooperation with students in the classroom (Crouch and Mazur, 2001). Wieman (2007) tried a more scientific approach. He encouraged students who had completed the preclass learning to find their own answers by solving in-class conceptual questions (Wieman, 2007). This educational model was also used in pharmacy, physiology, and biology in several universities, which showed the improvement effect of student's participation in classes and academic performance (Barral et al., 2018; Kugler et al., 2019; McLean et al., 2016). The introduction of FL into medical education made a particular turning point (Chowdhury et al., 2019). Many studies suggest that FL has increased student's motivation and engagement (Chen et al., 2017). A meta-analysis reported that FL is also associated with higher academic achievement compared to a traditional lecture (Chen et al., 2018).

The educational advantages of FL revealed in the previous studies are as follows (Chen et al., 2017; Chen et al., 2018; Hew and Lo, 2018; Jensen et al., 2015; Moffett and Mill, 2014). First, FL 
could change passive students into active ones. Students could increase their concentration in classes, motivation for classes, and change their attitude positively and actively. This is because it is based on self-directed participation in learning activities. Second, the integration of independent learning and communication activities could be promoted through student-student or studentteacher interaction. Third, students could study class contents repeatedly by way of online and offline activities and their understanding of the contents could be improved by performing advanced or supplementary activities. Fourth, it is possible to improve student's self-directed learning skills by participating in preclass learning and various activities in the classroom. Finally, teachers could perform level-differentiated or individualized learning, considering student's level of competence. It's because teachers could identify student's prelearning status by giving a quiz at classes and support students learn accordingly. Overall, these advantages make more students prefer FL to the traditional classroom (Ramnanan and Pound, 2017).

\section{CONCLUSIONS}

Before the digital media era, knowledge acquisition was possible only by taking classes in person. But we can learn anytime, anywhere if we have a smart device. Since the amount of knowledge has increased tremendously, the lifespan of knowledge is getting shorter and shorter and self-directed learning is becoming more important than contents studying for lifelong learning (Murad and Varkey, 2008). FL has been highlighted as an optimal educational method for meeting such future changes in the educational environment. The powerful transmission capability of video contents can enable students to implement appropriate prelearning and easily obtain learning outcomes through peer discussion at the classes (Roseth et al., 2008). In a non-face-to-face learning environment caused by COVID-19, online learning is inevitable. As in FL prelearning is usually done through online learning focusing on watching a video, online learning can be said to be appropriate in the present educational environment.

However, FL does not have its advantages only. Practically, it would be difficult for teachers to implement FL for every lecture in a course. Teachers need to make more efforts to prepare classes than just giving lecture, including preparing prelearning videos. Teachers should also consider cost-effectiveness, learning space design, and faculty development for optimizing outcomes (Persky and McLaughlin, 2017). FL cannot be uniformly applied to all classrooms due to differences in environment, capability, and cul- ture of each educational institution.

Nevertheless, FL must be a teaching modality suitable for students who require new learning methods. Educational outcomes can be effectively achieved by introducing FL. To achieve this goal, it is necessary to make efforts for applying FL more easily in a non-face-to-face environment.

\section{CONFLICT OF INTEREST}

No potential conflict of interest relevant to this article was reported.

\section{ACKNOWLEDGMENTS}

The authors received no financial support for this article.

\section{REFERENCES}

Barral AM, Ardi-Pastores VC, Simmons RE. Student learning in an accelerated introductory biology course is significantly enhanced by a flipped-learning environment. CBE Life Sci Educ 2018;17:ar38.

Bergmann J, Sams A. Flip your classroom: reach every student in every class every day. Oregon: International Society for Technology in Education; 2012.

Chen F, Lui AM, Martinelli SM. A systematic review of the effectiveness of flipped classrooms in medical education. Med Educ 2017;51:585597.

Chen KS, Monrouxe L, Lu YH, Jenq CC, Chang YJ, Chang YC, Chai PYC. Academic outcomes of flipped classroom learning: a meta-analysis. Med Educ 2018:52:910-924.

Chowdhury TA, Khan H, Druce MR, Drake WM, Rajakariar R, Thuraisingham R, Dobbie H, Parvanta L, Chinegwundoh F, Almushatat A, Warrens A, Alstead EM. Flipped learning: Turning medical education upside down. Future Healthc J 2019;6:192-195.

Crouch $\mathrm{CH}$, Mazur E. Peer instruction: ten years of experience and results. Am J Phys 2001;69:970-977.

Deslauriers L, Schelew E, Wieman C. Improved learning in a large-enrollment physics class. Science 2011;332:862-864.

Eapen ZJ, Vavalle JP, Harrington RA. Lecture halls without lectures. N Engl J Med 2012;367:677-679.

Goh CF, Ong ET. Flipped classroom as an effective approach in enhancing student learning of a pharmacy course with a historically low student pass rate. Curr Pharm Teach Learn 2019;11:621-629.

Hew KF, Lo CK. Flipped classroom improves student learning in health professions education: a meta-analysis. BMC Med Educ 2018;18:38 
Hinojo Lucena FJ, López Belmonte J, Fuentes Cabrera A, Trujillo Torres JM, Pozo Sánchez S. Academic effects of the use of flipped learning in physical education. Int J Environ Res Public Health 2019;17:276.

Jensen JL, Kummer TA, Godoy PDM. Improvements from a flipped classroom may simply be the fruits of active learning. CBE Life Sci Educ 2015;14:ar5.

Koh JHL, Scott N, Lucas A, Kataoka M, MacDonell S. Developing dietetic students' confidence in multicultural communication through flipped learning. Teach Learn Med 2021;33:67-77.

Kugler AJ, Gogineni HP, Garavalia LS. Learning outcomes and student preferences with flipped vs lecture/case teaching model in a block curriculum. Am J Pharm Educ 2019;83:7044.

Mazur E. Education. Farewell, lecture? Science 2009;323:50-51.

McLean S, Attardi SM, Faden L, Goldszmidt M. Flipped classrooms and student learning: not just surface gains. Adv Physiol Educ 2016;40:
47-55.

Moffett J, Mill AC. Evaluation of the flipped classroom approach in a veterinary professional skills course. Adv Med Educ Pract 2014;5:415-425.

Murad MH, Varkey P. Self-directed learning in health professions education. Ann Acad Med Singap 2008;37:580-590.

Persky AM, McLaughlin JE. The flipped classroom - from theory to practice in health professional education. Am J Pharm Educ 2017;81:118.

Ramnanan CJ, Pound LD. Advances in medical education and practice: student perceptions of the flipped classroom. Adv Med Educ Pract 2017;8:63-73.

Roseth CJ, Johnson DW, Johnson RT. Promoting early adolescents' achievement and peer relationships: the effects of cooperative, competitive, and individualistic goal structures. Psychol Bull 2008;134:223-246.

Wieman C. Why not try a scientific approach to science education? Change 2007;39:9-15. 